\title{
Research on the Determinants of Foreign Direct Investment Inflows of Gansu Province China
}

\author{
Yuxia $\mathrm{Hu}^{1}$ \\ ${ }^{1}$ School of Economics, Northwest University for Nationalities, Lanzhou, China \\ Correspondence: Yuxia Hu, Tutor, School of Economics, Northwest University for Nationalities, Lanzhou 730124, \\ China. E-mail: jkjkjk3723@yahoo.com.cn
}

Received: February 4, 2013

Accepted: March 26, 2013

Online Published: April 8, 2013

doi:10.5430/ijfr.v4n2p148

URL: http://dx.doi.org/10.5430/ijfr.v4n2p148

This work was supported by the Fundamental Research Funds for the Central Universities of Northwest University for Nationalities China under grants ZYZ2012011.

\begin{abstract}
Foreign Direct Investment has contributed significantly to Chinese economic development. Yet the geographic distribution of the FDI is quite uneven. Compared with the inward FDI in the eastern and mid regions of China, the western region has attracted less FDI. FDI is fuelling much of the rapid economic leap of the developed regions of China and the significant inequity grows further. There are many determinant factors to influence the FDI inflows. The essay takes Gansu province as an example, the author concludes that the core constraining factors of Gansu province in FDI attraction are, but not limited to, the economy development and openness degree, natural environment and the impact of industrial cluster, thus, the government of Gansu province should formulate corresponding measures to attract FDI inflows so as to produce optimal results and stimulate the economy growth.
\end{abstract}

Keywords: determinants, foreign direct investment inflows

\section{Introduction}

Foreign Direct Investment has contributed significantly to Chinese economic development. Yet the sector and geographic distribution of the FDI is quite uneven. Much majority of FDI in China is pinpointed in developed and coastal provinces as Guangdong, Jiangsu, Fujian and Shanghai, and the residual majority even immediately adjacent to the coastal areas is slightly touched. By the end of year 2010, the foreign-sponsored enterprises in China climbed up to the total of 710,641, and the actual utilized FDI amounted to US\$1051.2 million. The eastern regions took up the proportion of $83.3 \%$ and 86.5 respectively, and the mid-regions $10.7 \%$ and $8.1 \%$. With 12 provinces and cities as Chongqing, Sichuan, Guizhou, Yunnan, Tibet, Shanxi, Gansu, Qinghai, Xinjiang, Ningxia, Guangxi and Inner Mongolia, the western regions only covered 6\% and 5.4\% respectively. In the total western FDI inflows of 2010, Sichuan topped the list of all the western provinces and took the proportion of $37.4 \%$, followed by Chongqing $29.1 \%$, Shanxi $10.1 \%$, and Guangxi $8.4 \%$. Located in the north-west China, Gansu province is land-locked and adjacent to Qinghai, Tibet, Xinjiang, Ningxia and Inner Mongolia, the land area of which is around 4.69\% of the total area of China and ranks the seventh of all the provinces and cities of China. Gansu is world renowned for its minority groups and stocks economy of ethnic areas. Gansu province is well-endowed with many natural resources especially some rare precious metals, and most importantly, it builds up the business connections between China and the Republic of Mongolia. Yet the story of FDI in Gansu is not quite as rosy as what should be expected. By the end of the year 2010, the registered foreign enterprises of Gansu province totaled 2016, and the actual utilized FDI inflow amounted to US\$ 86 million, which nearly touched the rock bottom as compared with the other eleven provinces and cities of the western region.

In addition to the spur powers of FDI in Gansu province to its economy leap on the long run as likely evidenced by the true anecdotes of other provinces China, many other factors make this research paper practical and well-endowed with high significance, say, the land-locked geographic location, the comparatively low economy advancement pace, the high rate of illiteracy, the limited infrastructure and logistics, and the lower average GDP per capita etc. Thus, how to fuel the economy development, either in the short run or in the long run, is quite imminent. Based on the 
statistical data of various sources, this study portrays the inward FDI flows of Gansu province from the various perspectives and lists the underlying determinants. The first section of the study encompasses an introduction to the FDI inflows in Gansu province China. Section Two outlines the core constraints of the inward FDI flows. Section Three sketches some reflections about the concrete actions of Gansu province so as to further the FDI attraction yet tailed to the local economy development agenda.

\section{Literature Review}

A large number of literatures have empirically studied the FDI location choice in China. The idea of FDI agglomeration in certain regions or places can be traced back to as far as Marshall (1920), who pointed out the reasons of agglomeration are that firms pursuit internal and external economies of scale. Redding and Venables (2004) pointed out that the geographic location, thus the degree of openness will affect the flows of goods, factors and information, and will naturally affect the location choices of FDI. A large domestic literature has sprouted in order to offer explanations of the location of foreign direct investment. Wang and $\mathrm{Hu}$ (2005) used the data sample of foreign-funded enterprises in Jiangsu province and found these industries showed some degrees of heterogeneity in attracting FDI that more specialized industries tend to have more FDI agglomerated. Wei\& Jun (2008) in their empirical study of FDI in Anhui province held that the industrial structure was the main constraining factor to attract FDI inflows. He\& Tong (2008) chose the FDI location choices of the Yangtze River Delta, and drew the conclusion that the difference of aggregation factors, economic strength, manufacturing level, technical level and labor costs had a significantly positive power on the location of FDI, while the distance to Shanghai showed a negative impact. Zhang Jingping (2008) analyzed the impact of intellectual property protection of the host country, and kept the idea that a modest and efficient intellectual property protection mechanism would attract more FDI inflows.

Many scholars are trying to portray the internal reasons of differentiated inward FDI flows in different regions of China. Zhang and $\mathrm{Wu}$ (2005) in their essay concluded that temporary demand had speeded up FDI inflow. Gao Yanting (2008) proved the differentiated spur of FDI to the economic development of eastern and western regions China. Cui and Li (2010) focused on the contribution rate of FDI injection to GDP growth of the three regions of China. Dou Dengquan (2011) concluded that the influences of FDI on the recipient places include direct impacts and technology spillovers. Other Chinese scholars as Leihui (2006), Gong Xiaoying et al. (2011), Wan Lijuan (2011), Qu Yanlin et al. (2011) conducted their researches from the slightly different perspectives and drew similar conclusions that FDI had promoted the economic development of western regions to some extent.

In recent years, some Chinese scholars with a limited list of Xiangjun (2005), Zhenggang\& Wang Keling (2006), Chenhui\& Niu Shuwen (2010), He Yunfeng\& Shi Zhengye (2010) sparks their ideas and methodologies in their essays of Chinese versions in the narrowed perspective as exemplified by the Gansu province China, and their concluding remarks are as similar as that FDI inflows can definitely stimulate the economy development of Gansu province, yet there are many determining factors to hinder the FDI inflows. They further showed their concerns with the productivity initiatives in social dimensions and the coherent results.

The general literature review discloses that the scholars or practitioners of Gansu province have realized that the total cumulative FDI stocks definitely have positive effects on the economy growth, and they are trying to list some countermeasures for the increase of inward FDI flows. This essay, based on affirmative data, outlines the panorama of inward FDI flows in Gansu province and aims to formulate corresponding measures to multiply FDI inflows so as to further spur the local economy development.

\section{The FDI Inflows in Gansu Province}

Many policy-makers regard FDI attraction as an important element in their strategy for economic development, since FDI has gained a wide acceptance as an amalgamation of capital, technology, marketing and management. For Gansu province, the FDI inflows keep at a rather limited scale and vary from time to time.

Table 1. The real utilized FDI in the eleven provinces of north-west China from the year 2005 to 2010

Measurement Unit: US\$ million

\begin{tabular}{ccccccc}
\hline & 2005 & 2006 & 2007 & 2008 & 2009 & 2010 \\
\hline Inner & 407 & 500 & 579 & 763 & 950 & 910 \\
Mongolia & 609 & 760 & 929 & 1094 & 1210 & 1248 \\
Guangxi & 284 & 330 & 762 & 1005 & 1200 & 1567 \\
Chongqing & 663 & 800 & 1156 & 1960 & 2140 & 2593 \\
Sichuan & 663
\end{tabular}




\begin{tabular}{ccccccc} 
Guizhou & 103 & 120 & 120 & 142 & 160 & 186 \\
Yunnan & 290 & 380 & 454 & 553 & 680 & 778 \\
Tibet & 20 & 20 & 22 & 24 & 30 & 26 \\
Shanxi & 558 & 610 & 689 & 562 & 720 & 831 \\
Gansu & 137 & 100 & 106 & 128.42 & 150 & 186 \\
Qinghai & 27 & 50 & 73 & 103 & 80 & 86 \\
Ningxia & 154 & 150 & 80 & 88 & 100 & 97 \\
Xinjiang & 75 & 100 & 129 & 205 & 230 & 247 \\
\hline
\end{tabular}

Data Source: Statistical Yearbook of China 2005-2010

As evidenced from table 1, the actual utilized FDI inflow of western regions shows the up-soaring trend in the chosen sample years, yet with differentiated paces. Inner Mongolia and Chongqing seem to strengthen its inward FDI flows with high speed, while Tibet, Qinghai and Ningxia fluctuate in the FDI inflows and even stepped backward from time to time. Consequently we may deduct that the allotment of FDI inflows in the western region of China is quite uneven with the developed provinces and cities as the crux powers and the others slightly touched. Gansu province is positioned at nearly the rock bottom.

Table 2. The panorama of FDI inflows in the provinces of north-west China in the year 2011

\begin{tabular}{ccccc}
\hline Provinces & $\begin{array}{c}\text { Projects } \\
\text { (number) }\end{array}$ & Ratio(\%) & Actual Utilized FDI Inflows(US\$ Million) & Ratio(\%) \\
\hline Total & 1358 & 100 & 9022.5 & 100 \\
Sichuan & 379 & 27.9 & 3373.1 & 37.4 \\
Chongqing & 226 & 16.6 & 2627.2 & 29.1 \\
Shanxi & 142 & 10.5 & 909.8 & 10.1 \\
Guangxi & 190 & 14.0 & 759.1 & 8.4 \\
Yunnan & 166 & 12.2 & 600.5 & 6.7 \\
Inner Mongolia & 82 & 6.0 & 337.7 & 3.7 \\
Guizhou & 38 & 2.8 & 216.0 & 2.4 \\
Gansu & 28 & 2.1 & 126.2 & 1.4 \\
Ningxia & 25 & 1.8 & 40.3 & 0.5 \\
Xinjiang & 62 & 4.6 & 32.7 & 0.4 \\
\hline
\end{tabular}

Data Source: Official Statistical Data of the Related Provinces

Though Qinghai and Tibet are two provinces excluded from table 2 due to lack of the concerned statistical data, it is still quite clear that both FDI inflows and the number of the foreign-funded projects in Gansu province are quite limited and there exists huge distance between Gansu and the developed provinces in western region of China as Chongqing city, Sichuan and Shanxi provinces.

\section{The Constraints of FDI inflows in Gansu Province}

Much of the foreign furor over foreign-controlled enterprises in China is an offshoot of rich raw materials, comparatively cheap labor force, and the great market potentiality alleged by the huge population, which was reflected in the high tides of factories in coastal cities. The key determinant of the location of foreign direct investment is the investment environment which is usually as broad as to include political environment, economic environment, social environment, legal environment and natural environment. From the more concrete perspectives, the reasons for international investment activities are mainly as follows: to seek for market penetration, to base on resources-driven motives thus to outsource the fragments of the productions with huge resources or labor inputs, to pinpoint near the emerging consumer markets, to search worldwide for cost-effective production and increasingly flexible marketing netting, or to engage in techniques collaboration. There is a long list of determinants of FDI inflows in Gansu province as economic strengths, manufacturing level, technique level, labor costs, technique property protection mechanism, differentiated role of human resources and urbanization process, market size, public capital and so on. We synthesize the core constraining factors of Gansu province in FDI attraction as the economy development and openness degree, natural environment and the impact of industrial cluster. 


\subsection{The Economy Development and Degree of Economy Openness of Gansu Province}

Table 3. The foreign-related business and GDP of Gansu Province from the year 1999 to 2008

\begin{tabular}{cccccc}
\hline & & \multicolumn{3}{c}{ Measurement Unit: US\$ million } \\
\hline Year & $\begin{array}{c}\text { Total Volume of } \\
\text { Importation\& Exportation }\end{array}$ & $\begin{array}{c}\text { Overseas Contracted } \\
\text { Projects and Labor } \\
\text { Service Cooperation }\end{array}$ & $\begin{array}{c}\text { Total FDI } \\
\text { Inflows }\end{array}$ & $\begin{array}{c}\text { Foreign Tourism } \\
\text { Earnings }\end{array}$ & GDP \\
\hline 1999 & 406.23 & 56.64 & 41.04 & 37.35 & 11549.52 \\
2000 & 569.53 & 73.92 & 62.35 & 54.63 & 12716.21 \\
2001 & 778.87 & 53.34 & 74.39 & 44.81 & 13594.22 \\
2002 & 877.40 & 48.57 & 52.28 & 54.31 & 14883.82 \\
2003 & 1327.14 & 41.92 & 38.87 & 21.17 & 16905.80 \\
2004 & 1763.14 & 39.51 & 35.39 & 43.79 & 20392.51 \\
2005 & 2631.36 & 57.89 & 20.44 & 58.76 & 23585.12 \\
2006 & 3824.50 & 54.05 & 29.54 & 62.93 & 28458.75 \\
2007 & 5495.94 & 106.17 & 118.02 & 70.21 & 35578.69 \\
2008 & 6093.55 & 3032.21 & 128.42 & 60.34 & 5736.28 \\
\hline
\end{tabular}

Data Source: Statistical Yearbook of Gansu Province from the year 2000 to 2009

As evidenced by table 3, in the chosen time span, the four criteria of the foreign-related business of Gansu province are total volume of importation and exportation, the value of overseas contracted projects and labor service cooperation, the total FDI inflows and the overall foreign tourism earnings. All the four factors show that Gansu province has been developing steadily and increasingly in its foreign businesses and activities. The degree of economy openness is the weighted average of the ratio between the four determinants with the GDP respectively. Thus, the composite economy openness of Gansu province is in the up-soaring trend in the sample years, yet it is far below the developed provinces and regions of China. Furthermore it lags behind the average level of China as a whole with $2.24 \%$ and $28.13 \%$ respectively in the year $1999,12.45 \%$ and $55.05 \%$ respectively in the year 2008 . This is the most important constraint in limiting the FDI inflows of Gansu province.

\subsection{Natural Environment}

The environment features of Gansu province is that it is land-locked and adjacent to Qinghai, Tibet, Xinjiang, Ningxia and Inner Mongolia, the land area of which is around $4.69 \%$ of the total area of China and ranks the seventh of all the provinces and cities of China. Gansu is world renowned for its minority groups and stocks economy of ethnic areas. Gansu province is well-endowed with many natural resources especially some rare precious metals. What makes the difference is that geographic location and natural endowment of Gansu province have built-up its public image as an agricultural-oriented place and the industrial contributions a weak flicker. The primary industry has dominated a prominent position, thus the overall economy development of Gansu province lags behind other developed coastal provinces of China, and even behind the relatively developed provinces of western region of China as Shanxi, Sichuan, Guangxi Zhuang Autonomous Region and Yunnan etc. This can not, in all possibilities, attract the multinational corporations to make investment and the FDI inflows are rather limited.

\subsection{The Impact of Industrial Cluster}

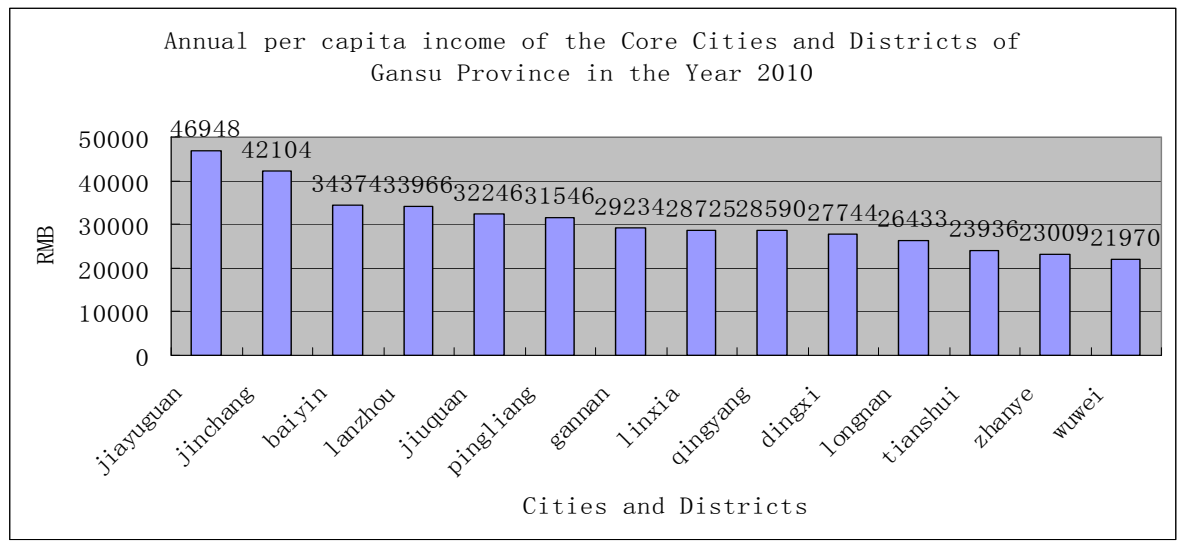

Figure 1. Annual per capita income of the core cities and districts of Gansu Province in the year 2010 Data Source: Statistical Yearbook of Gansu Province of the Year 2010 
Figure 1 alleges clearly that the annual per capita income of the fourteen cities and districts of Gansu province are nearly at the same level with Jiayuguan and Jinchang cities topping the list but only a bit higher in the chosen criterion. On one hand, this portrays that the main regions and cities of Gansu province are developing at the same pace, and the economy advancement has achieved the sustainable equilibrium. On the other hand, this facts show that we can not pinpoint the core economic powers of Gansu province, thus it is impossible to formulate industrial zoning and clusters. As it is the usual case, for any countries, provinces or cities, the core powers are playing the leading roles in FDI attraction, industrial structure strengthening, even the talents training and on-the-job education etc. yet in Gansu province, the quasi-cloning of the cities and regions has substantially eclipsed this radiation capacity, and consequently hinders the inward FDI flows to much extent.

\section{Conclusions and Corresponding Counter-measures}

Generally speaking, FDI is a significant engine for economic growth. The inward FDI acts as a complementary fund source together with domestic investment, which has partly exerted positive powers on economic growth. Yet even within the territory of one nation, the impact of FDI varies among provinces and cities, between industries and regions, depending on resource endowment, geographic location, region characteristics, labor force, and the policy environment as well. The government of Gansu province should take the corresponding measures to enlarge FDI inflows so as to facilitate the economic development.

\subsection{Improve the Industrial Structure and Broaden the FDI Sink-in Spheres}

As evidenced by the official Customs data of 2008, the total volume of the exports of Gansu province amounts to US\$70.72 million, and the agricultural products and the by-products totals US\$59.10 million and takes up the proportion of $83.57 \%$. In the same year, the actual utilized FDI is US\$128.42 million. Yet US\$ 109.82 million flows into the industrial sections as the supply of water, electricity, gas and mining, which accounts for $85.52 \%$ of the total inward FDI flows. This is well alleged that the exportation of Gansu province focuses on the low value-added commodities, while the FDI inflows are quite characterized by the primary industry. It is well known that, for any countries, provinces, or regions, the higher the development of the tertiary industry, the higher the level of economy development.

So the government of Gansu province should try to better its industrial structure, so as to keep the FDI inflows into optimal use. Firstly, to develop the traditional industrial sections is still indispensable, e.g., the manufacturing of traditional Chinese medicine, the wind energy industry, solar energy industry, tourism industry, foodstuff industry, the industry of flowers and plants etc. Furthermore, it may be expected that the strategically utilized FDI inflows shall definitely support the local firms to move up the global value ladder and try to sink into tertiary industry, such as the fertile hi-tech industries etc..

\subsection{Better the Investment Environment and Utilize the Benefits of FDI Inflows}

It is somewhat ominous that much of the foreign furor over foreign-controlled enterprises in some places of China is an offshoot of rich raw materials, comparatively cheap labor force, and the great market potentiality alleged by the huge population. The government officials of Gansu should make the regional investment environment more acceptable to foreign firms from the upstream resource extraction to service delivery. So, what comes firstly is to better the infrastructure construction, say, to enlarge road and rail density, to popularize the telecommunication web, to stabilize the supply of water, electricity, and gas etc.

\subsection{Cultivate Qualified Labor Force to Match the Requirements of FDI Utilization}

Gansu province is typical of huge reserve of labor force, yet with high ratio of illiteracy and the average education level is quite lower than that of other cities and provinces of China. Since the purpose of multinational corporations is to reduce costs, the regions with abundant and qualified labor force will own advantages to some extent. So the education level of the employed persons is rather important. As is well-known that positive effects of FDI occur only when the host region has a minimum threshold level of proficient human capital, who are highly proficient in technology diffusion, acquisition of product and process innovation, and better management practice. So the government of Gansu province should develop human resources to well match with the requirements of FDI utilization. To enhance the general education level and cement the on-the-job training and practice are most important. Furthermore, to authorize the universities and institutes in research\& development and give them the strong backbones in financial support, thus to further commercialize the advanced technologies into production usage are rather strident. 


\section{References}

Chen, Hui, \& Niu, Shuwen. (2010). Research on the Economy Openness Evaluation and Countermeasures-Exemplified by Gansu Province. Economic Issues, 6, (in Chinese).

Cui, Chenjia, \& Liling. (2010). Research on the Influence of FDI to GDP Growth of Eastern, Mid and Western Regions of China. District Economy, (1), (in Chinese).

Dou, Dengquan. (2011). Empirical Research on the Influence of FDI on the Economic Development of Western Regions of China. Academic Forum, (7), (in Chinese).

Gao, Yanting. (2008). Empirical Research on the Differentiated Influences of FDI on the Economic Development of Eastern and Western Regions of China. Jiangxi Social Science, (7), (in Chinese).

Gong, Xiaoying, \& Cheng, Jiawei. (2011). the Empirical Research of Coordinated Spur of FDI Inflows and Economy Development in the Western Regions China-Exemplified by the Guiyang City. The Western Forum, (2), (in Chinese).

He, Yi, \& Tong Mu. (2008). Dynamic and Path Selection of Industrial Transfer and Industrial Agglomeration. Journal of Commercial Research, 7, (in Chinese).

He, Yunfeng, \& Shi, Zhengye. (2010). Research on the Correlations between FDI and Economic Growth of Gansu Province. Gansu Science and Technology, 26(2), (in Chinese).

Lei, Hui. (2006). Crowing-in Effects of FDI Inflows of Eastern, Mid and Western Regions on the Domestic Investment China-Based on the Panel Data Analysis. China Soft Science, (2), (in Chinese).

Qu, Yanling, \& Shi, Benzhi. (2011). Research on the FDI Inflows Dilemma of Western Regions and the Countermeasures. The Ideological Front, (1), (in Chinese).

Wan, Lijuan. (2011). The Underlying Problems and Countermeasures of FDI Trade Effects of Westerns Regions China. Journal of Chongqing University, (5), (in Chinese)/

Wang, Weiwei, \& Hu, Jun. (2008). Empirical Research on the Influencing Factors of FDI: Evidence from Anhui. Journal of Nanhua University, 4, (in Chinese).

Xiang, Jun. (2005.The Underlying Problems and Countermeasures of FDI Inflows of Gansu Province. Journal of Lanzhou Commercial College, 21(6), (in Chinese).

Zhang, Jingping. (2008). How Do the Intellectual Property Protections of the Host Countries Affect FDI: Evidence from China. Market Survey, 3.

Zhang, Shenling, \& Wu Haiying. (2005). Empirical Research on the Influence of FDI on the Economic Development of Western Regions of China. Social Science in Ningxia, (1), (in Chinese).

Zheng, Gang, \& Wang, Keling. (2006). FDI Utilization and Countermeasures of Gansu Province in the Process of Urbanization. Social Science Review, 21(7), (in Chinese). 